Document downloaded from:

http://hdl.handle.net/10251/56589

This paper must be cited as:

Leiva García, R.; Akid, R.; Greenfield, D.; Gittens, J.; Muñoz Portero, MJ.; García Antón, J. (2012). Study of the sensitisation of a highly alloyed austenitic stainless steel, Alloy 926 (UNS N08926), by means of scanning electrochemical microscopy. Electrochimica Acta. 70:105-111. doi:10.1016/j.electacta.2012.03.036.

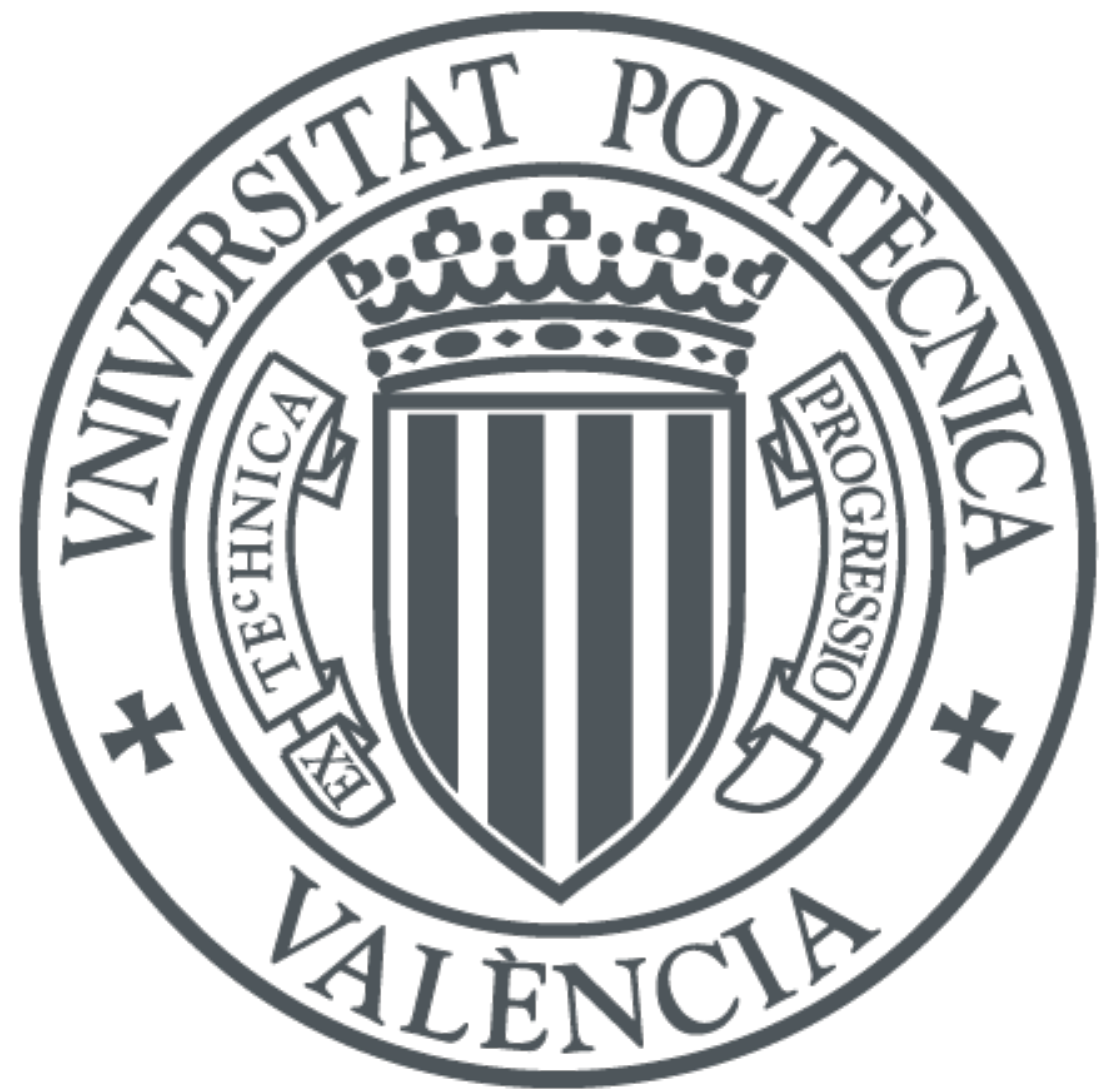

The final publication is available at

http://dx.doi.org/10.1016/j.electacta.2012.03.036

Copyright Elsevier

Additional Information 


\title{
STUDY OF THE SENSITISATION OF A HIGHLY ALLOYED AUSTENITIC STAINLESS STEEL, ALLOY 926 (UNS N08926), BY MEANS OF SCANNING ELECTROCHEMICAL MICROSCOPY
}

\author{
R. Leiva-García ${ }^{a}$, R. Akid ${ }^{b}$, D. Greenfield ${ }^{c}, J^{.}$Gittens $^{c}$ M.J. Muñoz-Portero ${ }^{a}$, J. \\ García-Antón ${ }^{\mathrm{a}}$ \\ ${ }^{a}$ Ingeniería Electroquímica y Corrosión (IEC), Departamento de Ingeniería Química y \\ Nuclear, E.T.S.I. Industriales, Universitat Politècnica de València E-46071 Valencia, \\ Spain \\ ${ }^{\mathrm{b}}$ Corrosion \& Protection Centre, School of Materials, University of Manchester, \\ Manchester M13 9PL, UK. \\ ${ }^{\mathrm{c}}$ Sheffield Hallam University, Centre for Corrosion Technology, Sheffield S1 1WB, \\ England, UK.
}

\begin{abstract}
The feedback mode of scanning electrochemical microscope (SECM) was applied to study differences in the reactivity of a highly alloyed austenitic stainless steel, Alloy 926 (UNS N08926), in its unsensitised and sensitised state. Alloy 926 was heated at 825 ${ }^{\circ} \mathrm{C}$ for 1 hour in an inert atmosphere in order to produce a sensitised metallurgical condition. Sensitisation was due to chromium carbide formation at the grain boundaries. The oxygen reduction reaction was used as an indicator to monitor the effect of the sensitisation process on the corrosion activity of the Alloy 926 surface in a $35 \mathrm{~g} \mathrm{l}^{-1} \mathrm{NaCl}$ solution. Higher oxygen consumption was observed above the sensitised sample than above the unsensitised sample due to differences in the oxide films of the two alloy conditions.
\end{abstract}

Keywords: Scanning Electrochemical Microscopy; Austenitic stainless steel; Sensitisation; Intergranular Corrosion

\section{Introduction}

Stainless steels offer good corrosion resistance, being primarily due to the presence of a low conductivity, surface bilayer structure which maintains the alloy in a metastable state of passivity therein providing corrosion resistance to the alloy. With respect to the composition of the bilayer formed on stainless steels, this consists of an inner layer of iron (III) and chromium (III) oxides enriched in chromium and an outer 
layer composed essentially of chromium hydroxide $\left(\mathrm{Cr}(\mathrm{OH})_{3}\right)$ [1, 2]. When austenitic stainless steels are incorrectly heat treated, in the temperature range between 500 and $900{ }^{\circ} \mathrm{C}$, chromium and carbon combine at the grain boundaries to form chromium carbides (typically $\mathrm{Cr}_{23} \mathrm{C}_{6}$ ), whilst simultaneously as these carbides form, chromium depletion occurs at the adjacent zones. This process is called sensitisation and leads to a decrease in the corrosion resistance of stainless steels, notably resistance to intergranular corrosion, being due to the depleted regions becoming anodic in the presence of an electrolyte [3-10].

In previous work [11], a highly alloyed austenitic stainless steel, Alloy 926 (UNS N08926), in the unsensitised and sensitised states, was tested in highly concentrated $\mathrm{LiBr}$ solutions ${ }^{1}$ in order to study the influence of the sensitisation process on the corrosion resistance of this steel. Despite the fact that the carbon content of this alloy is low, the high nickel content decreases the solubility of carbon leading to possible sensitisation and subsequent intergranular corrosion when improper heat treatments are carried out.

Conventional electrochemical techniques, such as electrochemical reactivation tests or cyclic potentiodynamic curves, have been widely used to study sensitisation and provide important information about the sensitisation processes [4, 6-10, 12-17]. Recent advances in the field of localised microelectrochemical techniques have provided the facility to acquire spatially resolved information about the corrosion processes occurring on the surface of the metal. Scanning Electrochemical Microscopy (SECM) is one such in-situ method that couples electrochemistry with scanning probe microscopy $[18,19]$. This technique consists of the movement of an ultramicroelectrode tip (UME) parallel to the surface of the sample, configured as an electrochemical cell in order to characterise the redox activity of the solid/liquid interface via the use of a selected mediator. Therefore, by using the SECM it is possible to analyse the passivity of the steel surface in its different metallurgical conditions (sensitised and unsensitised state) and the evolution of this passive film at a given working electrode potential, e.g., open circuit potential, in order to determine the evolution of the passive film with time.

The aim of this work was therefore to study the differences in the electrochemical activity of an Alloy 926 electrode surface in both the unsensitised and sensitised condition, under open circuit conditions in a naturally aerated aqueous

\footnotetext{
${ }^{1} \mathrm{LiBr}$ is used for applications such as refrigeration absorption machines (where $\mathrm{LiBr}$ can be used as the absorbent).
} 
chloride environment (35 $\mathrm{g} \mathrm{l}^{-1} \mathrm{NaCl}$ ) at $25{ }^{\circ} \mathrm{C}$. The following experiments were conducted, open circuit measurements, cathodic polarisation curves, cyclic voltammogram curves, and SECM line and area scans.

\section{Experimental Procedure}

\subsection{Materials}

A highly alloyed austenitic stainless steel, Alloy 926 (UNS N08926) supplied by Krupp VDM, was used for this study. The chemical composition (wt \%) of the alloy was: $20.8 \% \mathrm{Cr}, 24.90 \% \mathrm{Ni}, 0.90 \% \mathrm{Mn}, 0.35 \% \mathrm{Si}, 6.45 \% \mathrm{Mo}, 0.94$ \% Cu, $45.16 \%$ Fe, $0.02 \% \mathrm{P}, 0.01 \% \mathrm{C}$, and $0.18 \% \mathrm{~N}$. The electrodes were machined and shaped as rectangular prisms $30 \mathrm{~mm}$ high with a base surface of $0.36 \mathrm{~cm}^{2}$. Specimens were introduced into a silica tube in a furnace under an argon atmosphere, where they were heated to induce sensitisation by heat treating them at $825^{\circ} \mathrm{C}$ for a period of 1 hour. These conditions were selected based upon a previous study [9]. After heat treatment, an electrical connection was made to the specimen in order to allow electrochemical measurements to be made.

Individual unsensitised and sensitised samples were then mounted in epoxy resin as shown in Figure 1. Before every test, samples were wet abraded with silicon carbide paper up to \#1200, and then polished with alumina of 1 micron, before being finally rinsed with water and ethanol and dried with hot air.

\subsection{Open circuit measurements, cathodic curves, and potentiodynamic curves}

Electrochemical measurements were performed using a three electrode cell arrangement, with a saturated calomel electrode (SCE) as the reference electrode and the counter electrode made of platinum. Open circuit potential, cathodic polarisation curves and potentiodynamic curve measurements were obtained from both the unsensitised and sensitised samples in a $35 \mathrm{~g} \mathrm{l}^{-1} \mathrm{NaCl}$ solution at $25{ }^{\circ} \mathrm{C}$ using a multipotentiostat Uniscan PG 580 RM. All tests were carried out in naturally aerated solutions.

Open circuit potential measurements of Alloy 926 samples in the two tested states were made over a 10 hour period. 
In addition, cathodic and potentiodynamic curves were obtained with the open circuit potential being measured for 1 hour prior to the start of scans. Using the measured value of the OCP, cathodic curves were carried out from OCP to $-1 \mathrm{~V}_{\mathrm{SCE}}$ at a sweep rate of $0.1667 \mathrm{mV} \mathrm{s}^{-1}$. In the case of the potentiodynamic curves, scans were made from $-0.7 \mathrm{~V}$ vs SCE to $1 \mathrm{~V}$ vs SCE at $0.1667 \mathrm{mV} \mathrm{s}^{-1}$ sweep rate.

\subsection{SECM measurements}

SECM tests were performed using a Uniscan 370 workstation. The SECM was operated in "feedback mode". This technique measures a faradaic current at the

microdisk, while the tip is rastered over the specimen surface. A gold microelectrode tip of $10 \mu \mathrm{m}$ diameter, a sheet of platinum as counter-electrode, and a saturated SCE reference electrode were used. Samples were immersed in a $35 \mathrm{~g} \mathrm{l}^{-1} \mathrm{NaCl}$ solution at 25 ${ }^{\circ} \mathrm{C}$. All the tests were carried out in natural aerated solutions. Oxygen was used as the electrochemical mediator at the tip. The reduction of oxygen on the microelectrode was used to establish the height of the tip over the sample, and also to image the reactivity of the surface during the test. Oxygen reduction in aqueous solutions involves heterogeneous charge transfer processes coupled with homogeneous chemical reactions $[20,21]$. The cyclic voltammogram was recorded at a scan rate of $0.05 \mathrm{~V} \mathrm{~s}^{-1}$ from $0 \mathrm{~V}$ vs SCE to $-1 \mathrm{~V}$ vs SCE. Analysis of this data was then used in order to choose the polarisation potential of the tip.

The establishment of the operating distance of the tip to the sample surface was performed in relation to the different areas of the sample, notably (a) the resin close to the unsensitised alloy, (b) the unsensitised alloy, (c) the sensitised alloy and (d) the resin close to the sensitised alloy.

SECM scans were obtained by rastering the surface at steps of 75 microns in the $\mathrm{X}$ direction and 5 microns in the $\mathrm{Y}$ direction. The scanned area dimensions were 17200 $\mu \mathrm{m}$ x $50 \mu \mathrm{m}$ in $\mathrm{X}$ and $\mathrm{Y}$ directions, respectively. Scans were repeated three times over the same area during the test in order to assess any changes in the reactivity of the surface with the immersion time. Each scan was recorded by shifting the microelectrode tip from left to right. Hence, current maps were built as a composition of $\mathrm{X}$ line scans, which were stepwise moved in the $\mathrm{Y}$ direction. The time spent in each scan was two hours, and the total duration of the test was 6 hours. 


\section{Results and discussion}

\subsection{Open circuit measurements}

Figure 2 shows the open circuit potential measurements of Alloy 926 in its unsensitised and sensitised state. The potential of both samples shifts towards the positive direction, eventually stabilising with immersion time due to the formation of a passive film on the steel surface. This increase, often termed 'ennoblement', is generally associated with an increase of the cathodic reaction rate $\left(\mathrm{O}_{2}\right.$ reduction in aerated water, that favours oxide film formation) [22-24]. The cathodic reaction decreases as a result of the formation of a passive film which in turn increases the resistance to electron transfer through the film and decreases the electrochemical activity of the surface. The oxygen reduction reaction plays an important role during the passivation process, by producing a local current, which polarises the metal into the passive region [25-27].

The open circuit potential becomes more positive as a consequence of the sensitisation process and, consequently, the sensitised sample presents a higher cathodic activity. This increased activity is suggested to be related to metallurgical changes (Chromium carbides formation) that occur in the steel as a consequence of the heat treatment.

\subsection{Cathodic and potentiodynamic curves}

Figure 3 and Figure $\mathbf{4}$ present the cathodic polarisation and potentiodynamic curves of the unsensitised and sensitised samples. The results of the cathodic polarisation curves are in agreement with OCP measurements, because the cathodic activity is higher in the sensitised sample, being between 1.5 and 2 times higher than in the unheated sample. In the potential range where oxygen reduction occurs, the oxide film is partly reduced but an oxide film remains on the steel surface. According to the literature [28], oxygen reduction on polished surfaces is limited by the mass transport in the solution; however, on passivated surfaces, the oxygen reduction is limited by access of the oxygen to the metal surface and the electronic conductivity of the oxide film [28, 29]. Therefore, this result is indicative of the formation of a different passive film on the sensitised sample as opposed to that on the unsensitised sample. 
Furthermore, according to the potentiodynamic polarisation curves, the passivation current density is higher in the case of the sensitised sample (around 1.5 times higher than in the unsensitised sample), as shown in Figure 4. A higher passivation current density indicates a 'less-protective' passive film with higher electronic conductivity, this being due to the presence of areas depleted in alloying elements, notably chromium. This result was also observed in aqueous concentrated $\mathrm{LiBr}$ solutions in a previous study [11], where the sensitised Alloy 926 showed less corrosion resistance due to the sensitisation process.

\subsection{SECM tests}

The main cathodic reaction occurring during corrosion in aerated solutions is the reduction of dissolved oxygen:

$$
\mathrm{O}_{2}+2 \mathrm{H}_{2} \mathrm{O}+4 \mathrm{e}^{-} \rightarrow 4 \mathrm{OH}^{-}
$$

The progress of this reaction can be followed by setting the tip at $-0.7 \mathrm{~V}$ vs SCE. In these conditions the amperometric detection of oxygen is under the limiting current of reduction of oxygen, as confirmed by the cyclic voltammogram depicted in Figure 5. Therefore, with the tip polarised at $-0.7 \mathrm{~V}$ vs SCE it is possible to monitor, in solution, the consumption of oxygen with time at the surface of the alloy in either its sensitised or unsensitised condition.

Once the polarisation potential of the tip was selected, approach curves were carried out in order to choose the operating distance where the tip would raster above the specimen. The zero position of the tip, that is, where the approach curves begin, was an arbitrary position such that the influence of the specimen on the probe's response was not significant. From this zero position the tip was moved down towards the specimen; therefore, the approach curves record how the proximity of the tip to the specimen affects the diffusion of oxygen to the tip and hence the magnitude of the current. Figure 6 shows approach curves acquired at different locations, notably, over the resin close to the unsensitised alloy, over the unsensitised alloy, over the sensitised alloy, and over the resin close to the sensitised alloy. According to the approach curves the drop in the current measured at the tip occurs at a greater distance above the metal surface than above the resin as a consequence of cathodic reactions (oxygen reduction) that occur on the steel surface. Then, there is a competitive reaction in the consumption 
of oxygen, notably between the tip and the metal surface. In addition, based on the approach curves, the oxygen reduction is the highest over the surface of Alloy 926 in its sensitised state. Therefore, the selected operating distance of the microelectrode above the specimen was the distance where differences in the current among the registered approach curves were greatest, as shown in Figure 6.

Once the operating distance of the tip was selected, area scans of the sample were conducted, as shown in Figure 7. As described in the experimental procedure, scans were repeated three times over the sample surface in order to monitor changes in surface reactivity with immersion time. The magnitude of oxygen reduction occurring at the tip, when it was above the steel surface, is comparatively low compared to that above the epoxy resin. Furthermore, the amount of oxygen reduction on the tip increases when it passes from the sensitised sample to the unsensitised sample. Therefore, the consumption of oxygen is greater over the sensitised specimen, the increased consumption being associated with a higher cathodic activity. This result is in agreement with the higher cathodic current density observed in the sensitised sample obtained from the cathodic polarisation curve data. The higher cathodic activity indicates a greater electronic conductivity of the passive film formed on the sensitised sample. Several authors [28, 30-32], proposed that the reduction pathway is influenced by the surface composition of the electrode and oxides have an important role to play in the oxygen reduction kinetics. A homogeneous mixture of chromium oxide and hydroxide constitutes a barrier to oxygen reduction, whereas no diffusion barrier is observed when the surface is only partially covered with a non-reducible chromium oxide [33]. Therefore, any chromium depleted areas formed in the sensitised alloy can lead to the formation of a more conductive passive film that promotes higher oxygen reduction on the electrode surface. This observation confirms the results obtained from the cathodic (Figure 3) and potentiodynamic curves (Figure 4), where the cathodic current density and the passivation current density were higher in the the sensitised sample than in the unsensitised sample. Additionally, the presence of chromium carbides, which have a higher cathodic activity than the surrounding area [34, 35], may enhance the cathodic reduction of oxygen on the sensitised sample.

Line scans extracted from different points of the area scans are shown in Figure 8. At the beginning of the test, the minimum current registered at the tip over the sensitised sample is $2.30 \mathrm{nA}$ lower than over the unsensitised sample, after 230 minutes, this difference is only $0.15 \mathrm{nA}$. As explained previously, a lower current registered at 
the tip indicates higher consumption of oxygen on the metal surface. Therefore, the difference in the oxygen consumption between the heated and the unheated sample decreases with the time exposed to the electrolyte. Furthermore, there is a general decrease in the tip current with time, which may be due to a change in the oxygen content of the electrolyte. A small amount of electrolyte evaporation was noted during the test, which would lead to a corresponding increase in $\mathrm{NaCl}$ concentration and subsequent decrease in oxygen solubility in the electrolyte. Therefore, it is reasonable to normalise the values of the current registered in the tip to isolate the effect of the passive film formation in the evolution of the oxygen consumption. In order to do this, values of the current registered in the tip over the sensitised and unsensitised sample were divided by the current registered over the resin, eg, $\mathrm{I}_{\text {tip (metal) }} / \mathrm{I}_{\text {tip (resin). }}$.

Figure 9 presents the evolution of the open circuit potential and the normalised current measured above the unsensitised and sensitised samples. The normalised current measured at the tip over both samples increases with the immersion time, being indicative of a decrease of the consumption of oxygen on both samples. This decrease is possibly due to the passive film formation (inner chromium oxides and outer chromium hydroxide) that inhibits oxygen reduction and decreases electron transfer throughout it. This passive film formation is favoured by oxygen reduction and when the passive film grows it leads to a drop in the surface activity and oxygen consumption. Additionally, OCP values for both materials increase and this increase diminishes with immersion time due to the passive film formation. According to the literature [22-24], an increase in OCP is associated with an increase in the rate of the cathodic reaction. Therefore, when the passive film grows and diminishes the cathodic activity of the electrode surface, the rate of change of the OCP would also be expected to diminish.

With the formation of the oxide film on the sensitised sample, differences in the oxygen consumption between both materials decrease due to the inhibition of the oxygen reduction reaction. At the end of the test, values of oxygen consumption of the sensitised and unsensitised Alloy 926 are quite similar due to the formation of a film of chromium oxides and hydroxides that diminishes the electronic conductivity and decreases the oxygen diffusion.

Hence, oxide film formation becomes slower as a consequence of the sensitisation process, leading to a higher oxygen reduction reaction rate during immersion in an aerated $35 \mathrm{~g} \mathrm{l}^{-1} \mathrm{NaCl}$ solution. 


\section{Conclusions}

- Sensitised Alloy 926 presents higher OCP values than the unsensitised Alloy 926, the OCP increase being associated with an increase of the rate of the cathodic reaction and formation of a passive film.

- The oxygen reduction depends on the properties of the electrode surface, which are governed by the composition of the Alloy 926 and any heat treatments (sensitisation processes).

- According to the SECM data, the oxygen reduction rate becomes greater on Alloy 926 as a consequence of the heat treatment. This is due to the formation of a more conductive passive film on the sensitised Alloy 926.

- OCP enoblement and oxygen reduction rate decrease with immersion time as a consequence of the formation of an oxide film, this decrease being faster in the unsensitised Alloy 926.

- Therefore, according to the results obtained from this work, the sensitisation process of Alloy 926 produces morphological changes that lead to differences in the passive film formation of Alloy 926 before and after the heat treatment.

Acknowledgments: We wish to express our gratitude to MICINN (CTQ2009-07518, BES2007-16321) for its financial support during the stay at Sheffield Hallam University, to Universitat Politècnica de València (CEI-01-11), to Dr. Oliver Lewis from Sheffield Hallam University, and to Dr. Helena Alves from Krupp VDM for supplying the materials.

\section{References}

[1] C.R. Clayton, I. Olefjord, in: P. Marcus, J. Oudar (Eds.), Corrosion Mechanisms in Theory and Practice, Marcel Decker, New York, 1995, pp. 173-199.

[2] E. DeVito, P. Marcus, Surf. Interf. Anal. 19 (1992) 403.

[3] H. Shaikh, B.P.C. Rao, S. Gupta, R.P. George, S. Venugopal, B. Sasi, T. Jayakumar, H.S. Khatak. British Corrosion Journal 37 (2002) 129-140.

[4] A.S. Lima, A.M. Nascimento, H.F.G. Abreu, P. De Lima-Neto. J. Mat. Sci. 40 (2005) 139-144.

[5] N. Parvathavarthini, R.K. Dayal, H.S. Khatak, V. Shankar, V.Shanmungan. J. Nucl. Mat. 355 (2006) 68-82.

[6] H. Sidhon, T. Amadou, H. Sahlalaoui, C. Braham. Metall. Mater. Trans. A 38A (2007) 1269-1280. 
[7] R.V.S. Rao, N. Parvathavarthini, M.G. Pujar, R.K. Dayal, H.S. Khatak, R. Kaul, P. Ganesh, A.K. Nath. Surf. Eng. 23 (2007) 83-92.

[8] J. Stella, J. Cerezo, E. Rodríguez. NDT\&E international 42 (2009) 267-274.

[9] R. Leiva-García, M.J. Muñoz-Portero, J. García-Antón. Corros. Sci. 51 (2009) 2080-2091.

[10] S. Li, L. Li, S.R. Yu. R. Akid, H.B. Xia. Corros. Sci. 53 (2011) 99-104.

[11] R. Leiva-García, M.J. Muñoz-Portero, J. García-Antón. Int. J. Electrochem. Sci. 6 (2011) 442-460.

[12] A.S.M. Paroni, N. Alonso-Falleiros, R. Magnabosco. Corrosion 62 (2006) 10391046.

[13] H. Shaikh, G. George, F. Shneider, K. Mummert, H.S. Khatak. Transactions of the Indian Institute of Metals 54 (2001) 27-39.

[14] P. Záhumensky, S. Tuleja, J. Országova, J. Janovec, V. Magula. Corrosion 57 (2001) 874-883.

[15] M. Matula, Z. Stonawska, L. Tuma, C. Dagbert, L. Hyspecka, J. Galland. Electrochemical testing of sensitization to intergranular corrosion in stainless steel. Eurocorr 2001 Riva del Garda, Italy. (2001).

[16] H. Kanematsu, T. Kobayashi, K. Murakami, T. Oki. Corrosion Reviews 18 (2000) 53-64.

[17] Z. Fang, Y.S. Wu, L. Zhang, J.Q. Li. Corrosion 54 (1998) 339-346.

[18] B.R. Horrocks, in; A.J. Bard, M. Stratmann, P.R.Unwin (Eds). Encyclopedia of Electrochemistry Vol. 3 (2003), Weinhein, Wiley-VCH p. 444.

[19] A.J. Bard, M.V.Mirkin (Eds). Scanning Electrochemical Microscopy. (2001), New York, Marcel Dekker.

[20] J.J. Santana, J. González-Guzmán, L. Fernández Mérida, S. González, R.M. Souto. Electrochim. Acta 55 (2010) 4448-4494.

[21] J.P. Hoare. The electrochemistry of oxygen. (1968), New York, Interscience.

[22] W.H. Dickinson, F. Caccavo, Z. Lewandowski. Corros. Sci. 38 (1996) 1407-1422.

[23] C. Marconnet, C. Dagbert, M. Roy, D. Féron. Corros. Sci. 50 (2008) 2342-2352.

[24] S.C. Dexter, G.Y. Gao. Corrosion 44 (1988) 717.

[25] U.R. Evans. Electrochim. Acta 16 (1971) 1825-1840.

[26] M. Stern. J. Electrochem. Soc. 105 (1958) 638-647.

[27] B.S. Corvino jr, M. Rosen, T.J. Driscoll, T.C. Murphy, and C.R. Molock. Corros. Sci. 26 (1986) 95-107.

[28] N. Le Bozec, C. Compère, M. L`Her, A. Laoueman, D. Costa, P. Marcus. Corros. Sci. 43 (2001) 765-786.

[29] M. Okuyama, S. Haruyama. Corros. Sci. 31 (1990) 521-526.

[30] S.L.J. Gojkovic, S.K. Zecevic, M.D. Obradovic, D.M. Drazic. Corros. Sci. 40 (1998) 849-860

[31] E.J. Calvo D.J. Schiffrin. J. Electroanal. Chem. 163 (1984) 257.

[32] S. Zecevic, D.M. Drazic, S.Lj. Gojkovic. J. Electroanal. Chem. 265 (1989) 179193.

[33] N. Ramasubramanian, N. Preocanin, R.D. Davidson. J. Electrochem. Soc. 132 (1985) 793-798.

[34] E. Otero-Huerta. Corrosion y degracion de los materiales. Madrid (1997) Ed.Sintesis.

[35] V. Cihal. Materials Science Monographs 18. Intergranular corrosion of steels and alloys Prague (1984). Ed. Elsevier. 


\section{List of Figures}

Figure 1. Schematic diagram of the working electrode tested by SECM. Unsensitised sample on the left side.

Figure 2. Register of the open circuit potential of the unsensitised and sensitised Alloy 926 in the $35 \mathrm{~g} \mathrm{l}^{-1} \mathrm{NaCl}$ solution at $25^{\circ} \mathrm{C}$.

Figure 3. Cathodic curves of the unsensitised and sensitised Alloy 926 in $35 \mathrm{~g} \mathrm{l}^{-1} \mathrm{NaCl}$ solution at $25^{\circ} \mathrm{C}$.

Figure 4. Potentiodynamic curves of the unsensitised and sensitised Alloy 926 in $35 \mathrm{~g} \mathrm{l}^{-}$ ${ }^{1} \mathrm{NaCl}$ solution at $25^{\circ} \mathrm{C}$.

Figure 5. Cyclic voltammogram measured at the SECM tip immersed in $35 \mathrm{~g} \mathrm{l}^{-1}$ solution at $25^{\circ} \mathrm{C}$.

Figure 6. Approach curves carried out over the different areas of the specimen in $35 \mathrm{~g} \mathrm{l}^{-}$ ${ }^{1} \mathrm{NaCl}$ solution at $25^{\circ} \mathrm{C}$.

Figure 7. SECM area scans of oxygen reduction current measured above the specimen in the $35 \mathrm{~g} \mathrm{l}^{-1} \mathrm{NaCl}$ solution at $25^{\circ} \mathrm{C}$.

Figure 8. Line scans above different lines of the scanned specimen surface obtained at every scan in the $35 \mathrm{~g} \mathrm{l}^{-1} \mathrm{NaCl}$ solution at $25^{\circ} \mathrm{C}$.

Figure 9. Evolution of the normalised current measured at the tip above the different areas of the specimen with immersion time and register of the open circuit potential of the unsensitised and sensitised Alloy 926 in $35 \mathrm{~g} \mathrm{l}^{-1} \mathrm{NaCl}$ solution at $25^{\circ} \mathrm{C}$. 


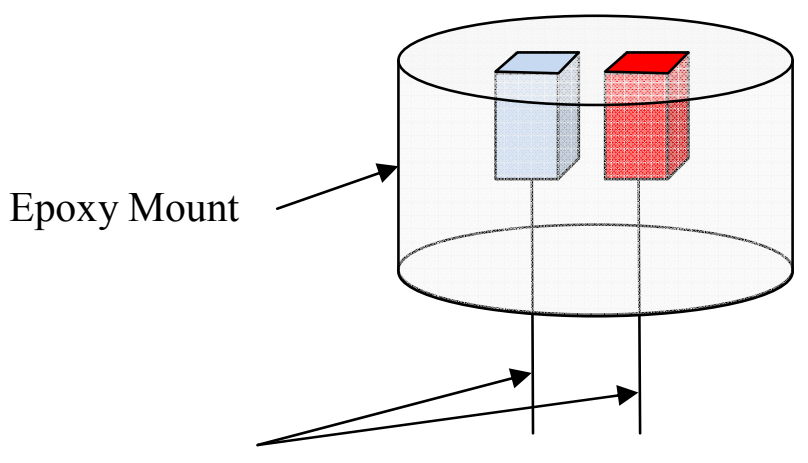

Electrical Connections

Figure 1. Schematic diagram of the working electrode tested by SECM. As-received sample on the left side. 


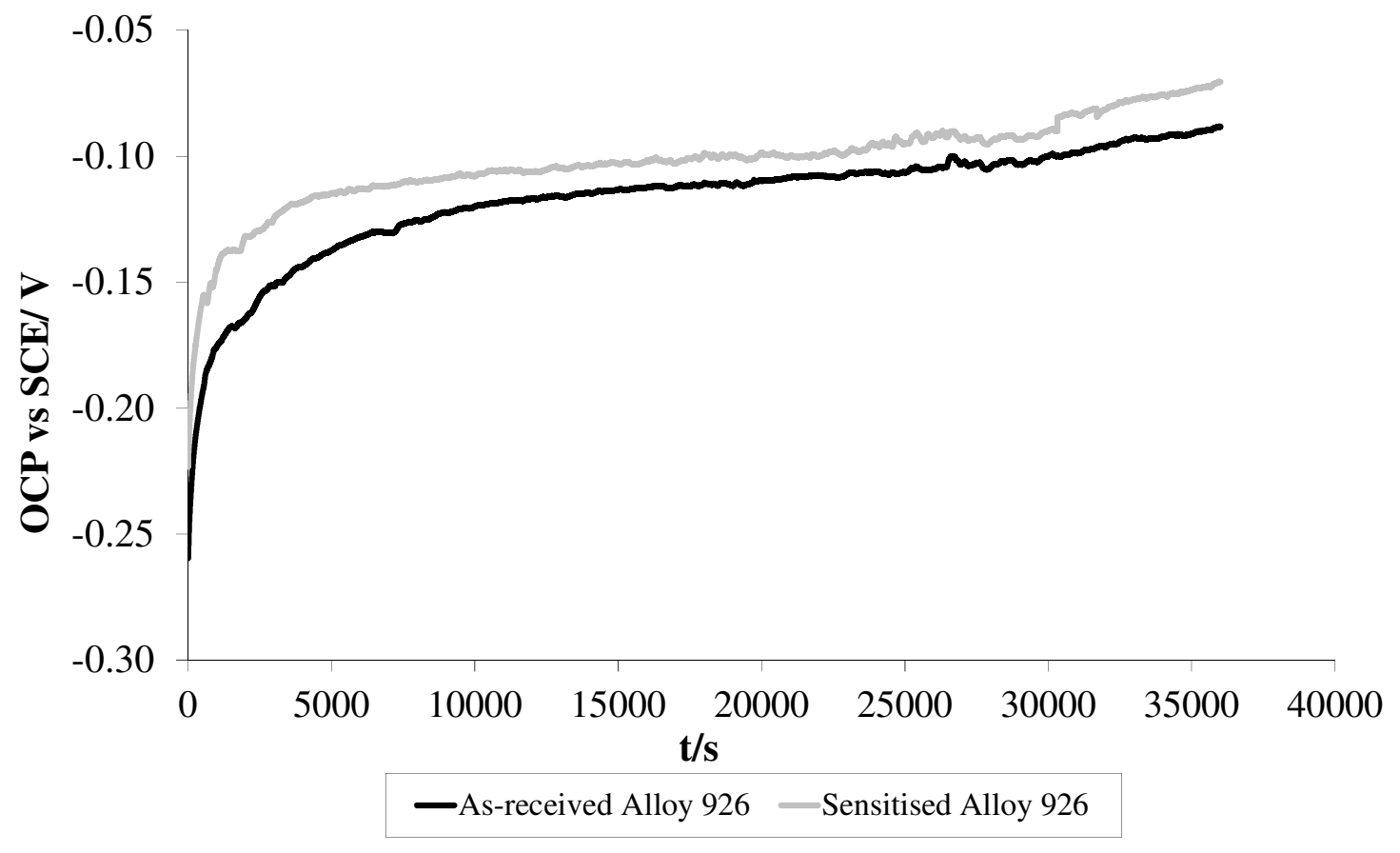

Figure 2. Register of the open circuit potential of the as-received and sensitised Alloy 926 in the $35 \mathrm{~g} \mathrm{l}^{-1} \mathrm{NaCl}$ solution at $25^{\circ} \mathrm{C}$. 


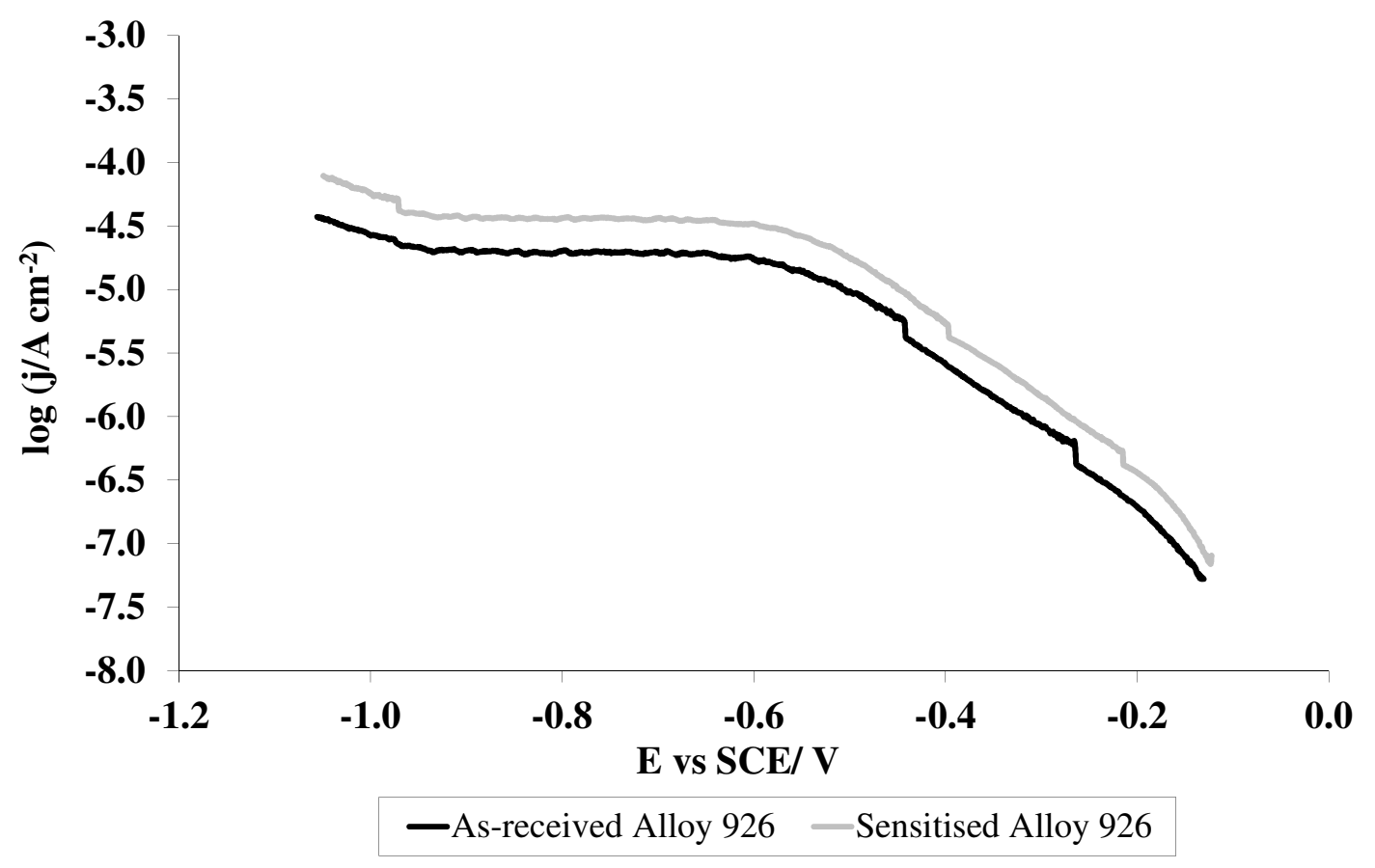

Figure 3. Cathodic curves of the as-received and sensitised Alloy 926 in the $35 \mathrm{~g} \mathrm{l}^{-1}$ $\mathrm{NaCl}$ solution at $25^{\circ} \mathrm{C}$. 


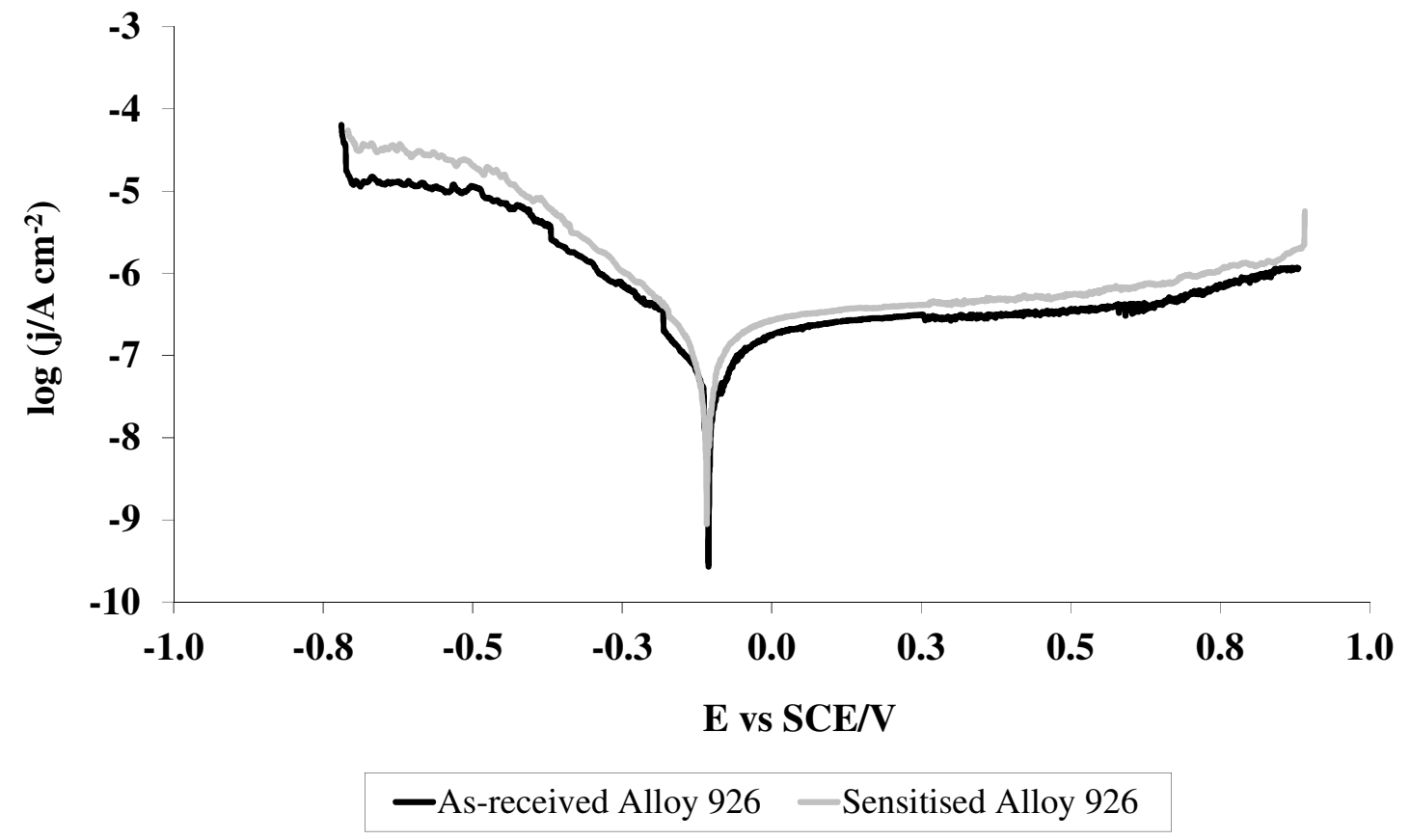

Figure 4. Potentiodynamic curves of the unsensitised and sensitised Alloy 926 in the 35 g $1^{-1} \mathrm{NaCl}$ solution at $25^{\circ} \mathrm{C}$. 


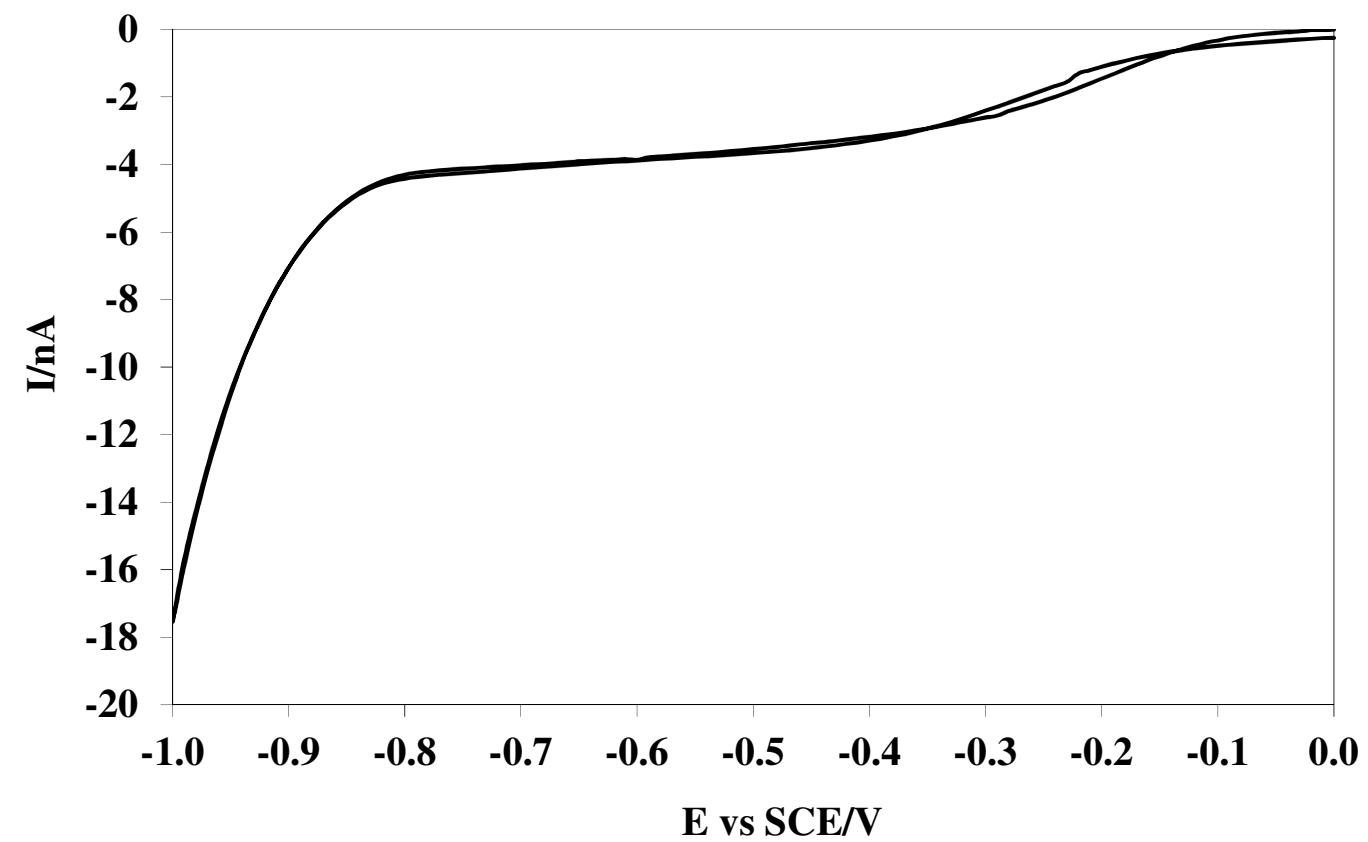

Figure 5. Cyclic voltammogram measured at the SECM tip immersed in the $35 \mathrm{~g} \mathrm{l}^{-1}$ solution at $25^{\circ} \mathrm{C}$. 


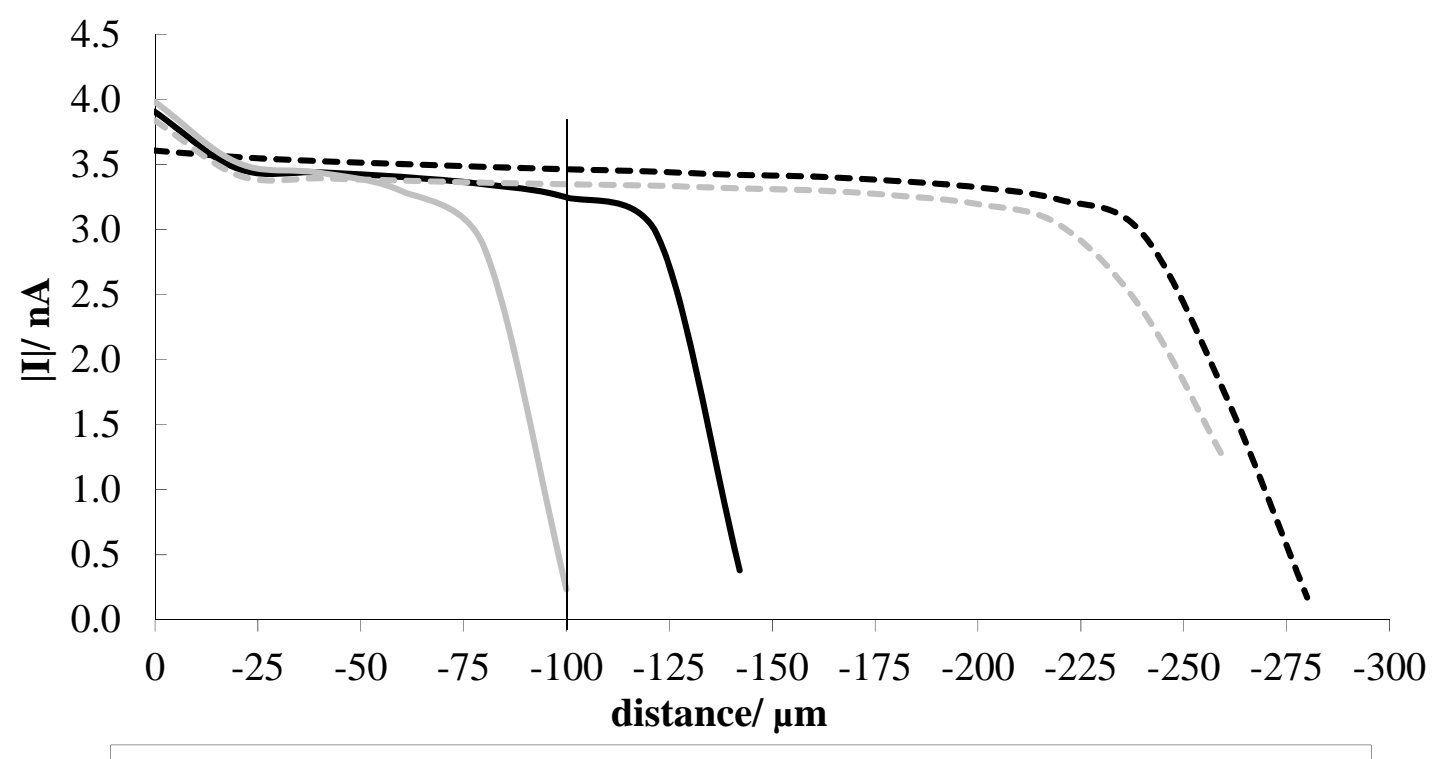

--・Resin 1 —As-received Alloy 926 —Sensitised Alloy 926 - Resin 2

Figure 6. Approach curves carried out over the different areas of the specimen in the 35 g ${ }^{-1} \mathrm{NaCl}$ solution at $25^{\circ} \mathrm{C}$. 


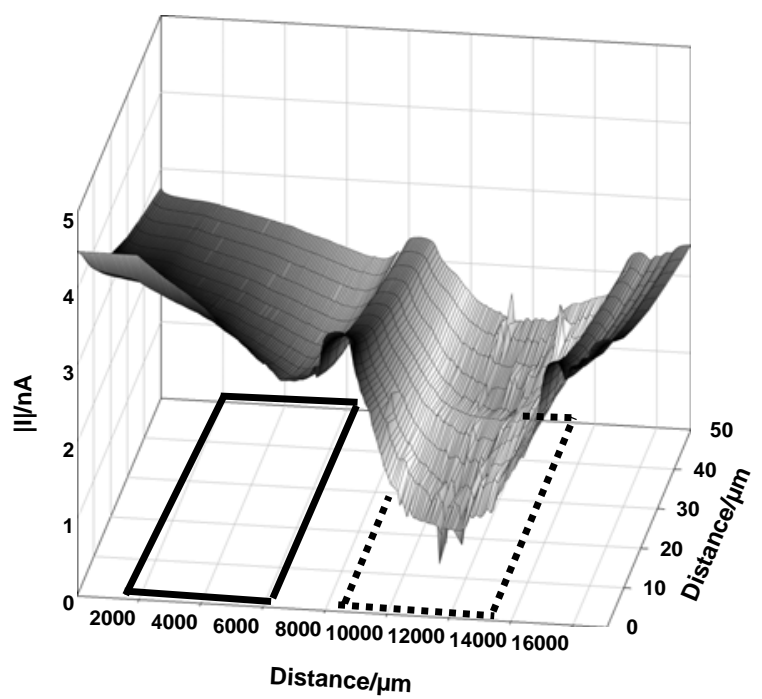

a) First scan

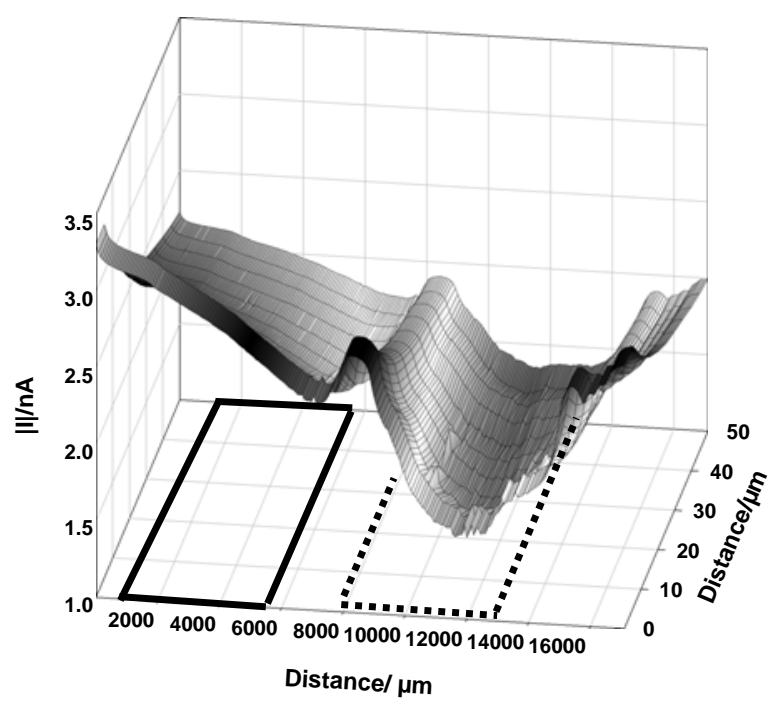

b) Second scan

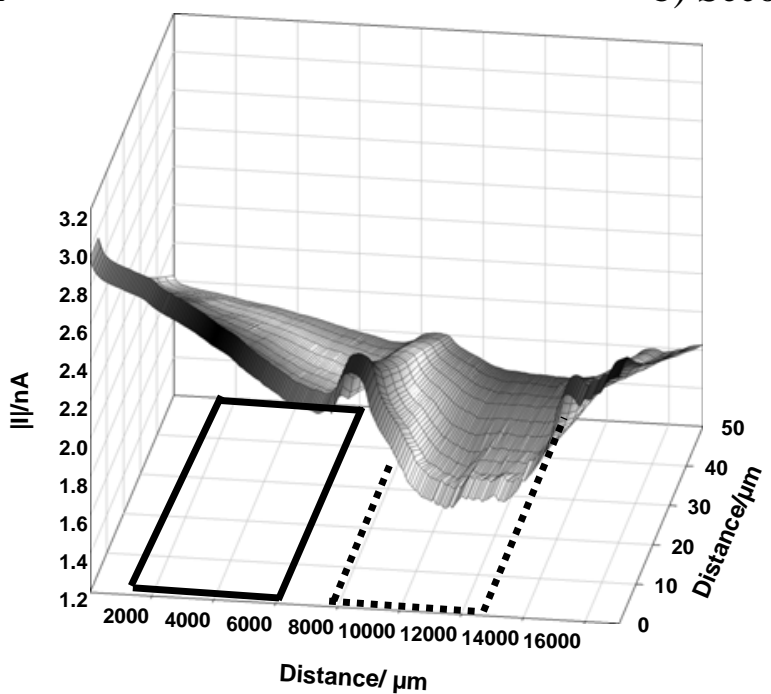

c) Third scan

As-received Alloy 926 - . - Sensitised Alloy 926

Figure 7. SECM area scans of oxygen reduction current measured above the specimen in the $35 \mathrm{~g} \mathrm{l}^{-1} \mathrm{NaCl}$ solution at $25^{\circ} \mathrm{C}$. 
$\mathbf{y}=\mathbf{0}$ microns

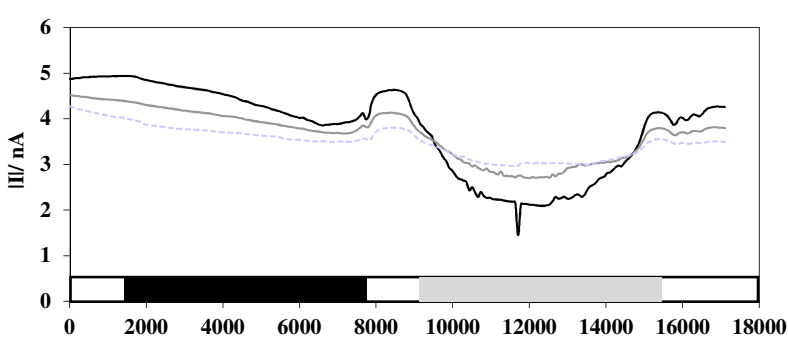

distance/ $\mu \mathrm{m}$

-1st scan $\quad$-2nd scan $\quad-3$ rd scan

$\mathbf{y}=\mathbf{3 0}$ microns

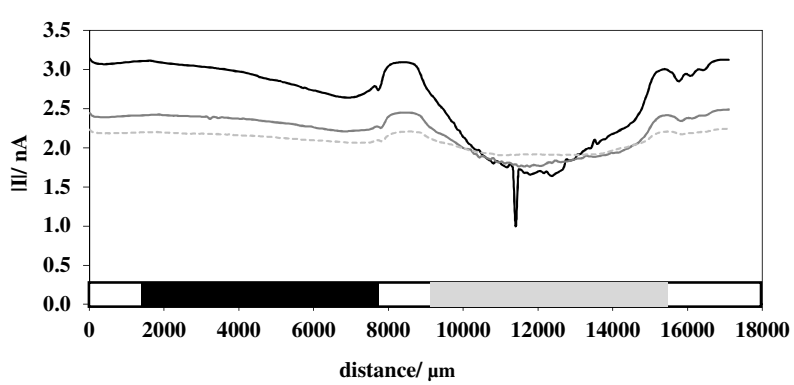

-1st scan $\quad$-2nd scan $\quad---3$ rd scan $\mathbf{y}=\mathbf{1 5}$ microns

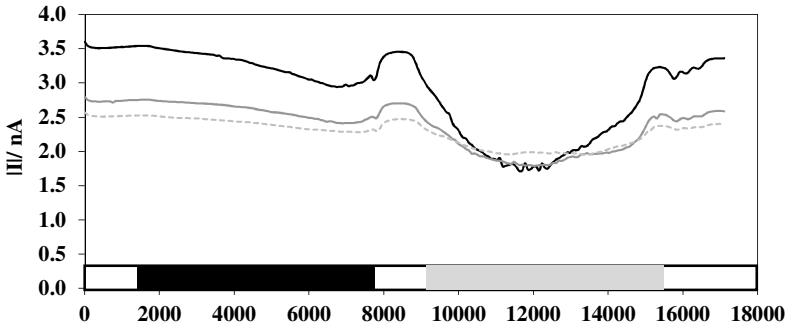

distance/ $\mu \mathrm{m}$

-1st scan $\quad$-2nd scan $-\cdots--3$ rd scan

$y=45$ microns

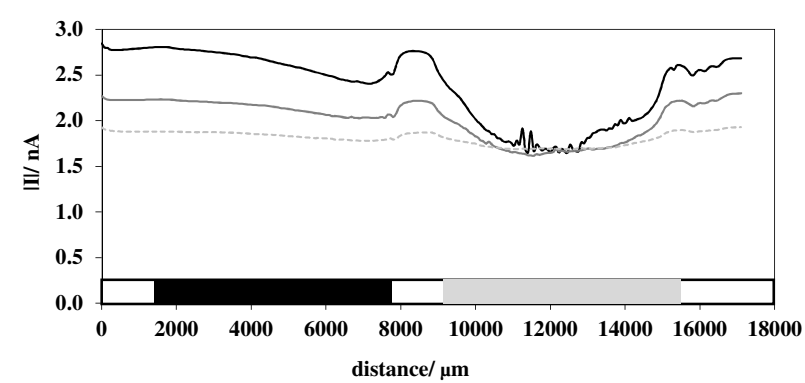

-1st scan $\quad$-2nd scan $\quad----3$ rd scan

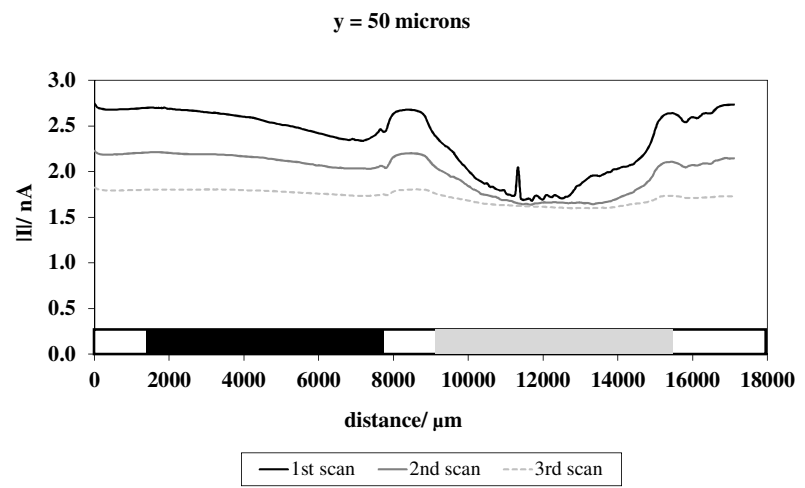

As-received Alloy 926

Sensitised Alloy 926

Figure 8. Line scans above different lines of the scanned specimen surface obtained at every scan in the $35 \mathrm{~g} \mathrm{l}^{-1} \mathrm{NaCl}$ solution at $25^{\circ} \mathrm{C}$. 


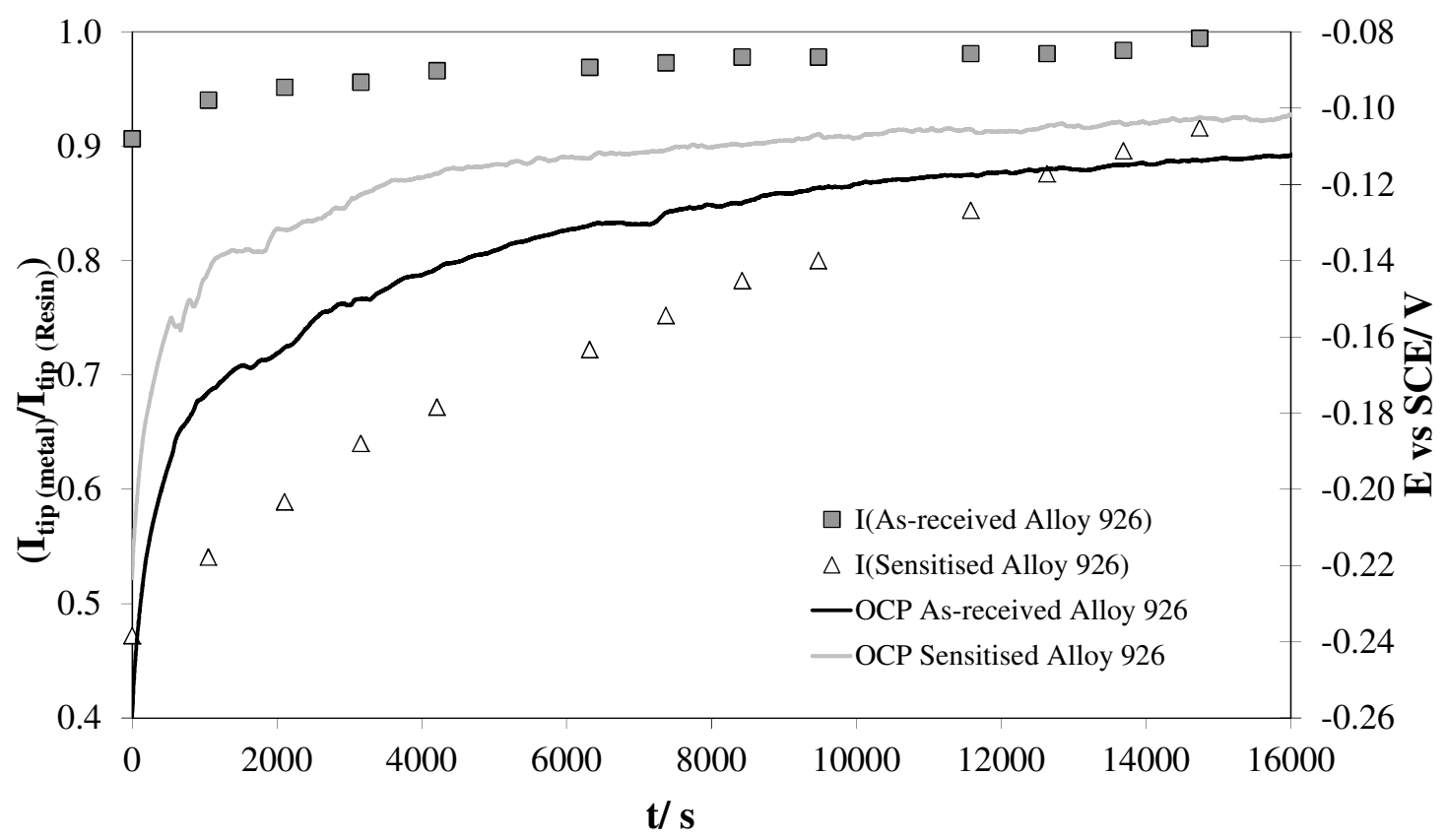

Figure 9. Evolution of the normalised current measured in the tip above the different areas of the specimen with immersion time and register of the open circuit potential of the as-received and sensitised Alloy 926 in the $35 \mathrm{~g} \mathrm{l}^{-1} \mathrm{NaCl}$ solution at $25^{\circ} \mathrm{C}$. 